"Przegląd Prawa Konstytucyjnego"

- Nr $3(19) / 2014$

\title{
Sprawozdanie
}

\section{International Conference Unconditionally Paid Basic Income or Entitlement to Workplace: A Constitutional Question, Vienna, Austria, 16-17 December 2013}

This comparative subject was discussed at a conference in Vienna, hosted by the Sonnenfels Center for the Study of Public Law and Economics at the University of Vienna, on December 16 and 17, 2013. The question of basic income or job guarantee was explored in the context of proposals in Austria in the 1980s to entrench the right to a workplace for citizens into the nation's constitution. What exactly would this mean in practical terms, and how does a universal or unconditional basic income (UBI) differ from this proposal?

The UBI concept has gained some strength in the past two decades after having largely disappeared from the public and academic discourse in the mid to late 1970s. Prominent figures such as Martin Luther King Jr., renowned economists such as John Kenneth Galbraith and many others from diverse perspectives and for numerous different reasons supported the idea then.

A largely unnoticed comparison with the job guarantee (JG) constitutional initiative in Austria, which eventually failed to materialize, is the successful modification of the Alaska state constitution at the end of the 1970s and early 1980s to provide a unique form of basic income to citizens. Although the Alaska model does not meet the criteria of what modern UBI proponents advocate in terms of annual financial amount, it nevertheless provides a precedent for a universal payment annually to all members in the state (including children) which can be augmented in numerous ways, and which can be replicated in other parts of the world. According to the main protagonist (former Governor Jay Hammond) of the universal Alaska Dividend and 
the state's Permanent Fund which supports this annual payment to all Alaskans, the Dividend would be much higher if implemented in the manner he originally proposed and it would approximate a proper UBI today.

The recent successful organizational effort in Switzerland to gather enough signatures to trigger a national referendum on basic income was also missing from discussion at the conference in Vienna as an important focal point of public law, constitutional change and the intersection with UBI.

Participants from Japan, Israel, the United States and different parts of Europe discussed entitlement to workplace or JG in Vienna, often without sufficient detail of the JG proposal, but rather with criticism of the UBI option and particularly its 'potential' impacts upon work ethic. These criticisms based upon the work ethic argument largely failed to acknowledge the large amount of empirical work that has dispelled this argument and concern (some may call it bias) where UBI experiments were conducted in different parts of the world, including in Canada and the United States.

JG proponents at the conference alluded to the need for people to work and stressed the importance of economic growth. What they failed to consider is that not all work is done in a labour-market exclusively, that many important forms of work are conducted outside of a labour-market, and that many forms of labour-market work can have very detrimental effects over the long-term upon the economy (short term gains of many mining operations at the expense of long-term productivity of lost farmland, or the pollution of freshwater reserves as an example).

One argument for UBI in this regard is that it can enable the many invaluable forms of non-labour-market work that are being crowded out and increasingly commodified into the labour-market with negative consequences. A healthier balance between labour-market and decommodified or non-labour-market work can be achieved with UBI, whereas the job guarantee model appears to solidify what many view as an unsustainable and unhealthy trend of excessive marketization of work as well as many other aspects of life.

Another common argument is that society is currently wealthy enough and technologically advanced to provide the "basic" needs of all without condition or wasteful, stigmatizing and often duplicating bureaucracies. The cost-savings of eliminating many of the most ineffective and coercive bure- 
aucracies of this sort would often be better directed towards increasing the financial payments to those in need in unconditional fashion.

The final result of this conference was that Job Guarantee proposals were not discussed in any detail, but only affirmed as the better option by many participants, and often only by way of misplaced criticism of basic income, primarily focused on the largely disproven work ethic argument. It was concluded that JG proposals have an inescapable coercive element not differing in significant ways from the status quo welfare programs, and that UBI escapes this coercion trap imposed by the bureaucratic state. The Alaska - and potentially Swiss - constitutional models and proposals for UBI represent a lost opportunity for substantive discussion to have occurred at this conference, which perhaps can be included as one element of a subsequent conference investigating constitutional-legal solutions to the jobs, quality work and income security crises faced globally.

One last point worth mention is that basic income increasingly serves as a potential corrective to ecological imperatives in the analyses of many scholars. This was one of the main reasons for the UBI/Dividend proposal in Alaska - to curb the excessive growth of developers and natural resource exploitation by saving a large portion of the profits for future generations and giving the current generation a partial dividend from these savings. Hammond's intention was to constitutionally capture a much higher portion of these economic rents for citizens in order to mitigate ecological harm and meet the terms of distributive justice. This ecological consideration ought to be given more attention.

Richard Pereira University of Birmingham 